\title{
NEW FUNCTIONALIZED GLASS FIBERS EMPLOYING CALIXARENIC SYSTEMS
}

\author{
RALUCA ANAMARIA SEPTELEANa, MYRAT VELNAZAROV ${ }^{a}$, \\ DOINA PRODAN ${ }^{\mathrm{b}}$, IOANA PERHAITA ${ }^{\mathrm{b}}$, OVIDIU NEMES ${ }^{\mathrm{c} *}$, \\ MARIOARA MOLDOVAN ${ }^{\mathrm{b} *}$
}

\begin{abstract}
New precursors for functionalized grass fibres were obtained through deposition of functionalized calix[4]arenes on G14 short glass fibers. The methods employed for the preparation as well as the characterization by thermal analysis, FT-IR spectroscopy, TEM and SEM microscopy of the newly obtained materials is presented.
\end{abstract}

Keywords: calixarenes, functionalized glass fibers, thermal analyses, electronic microscopy

\section{INTRODUCTION}

Calix[n]arenes macrocyclic compounds obtained by the condensation of para- substituted phenol with formaldehyde or para-formaldehyde, [1] can be functionalized with a large number of organic or organometallic groups $[2,3]$, at both the lower rim (the hydroxyl groups) or the upper rim (the para position of the phenyl rings) leading to an important class of organic compounds. Their characteristic structure, namely the existence of a hydrophobic cavity which can be tuned in size by the number of phenolic units $(n=4-20)$ as well as the type of the functional groups grafted onto the aromatic rings, makes this class of compounds versatile in a large number of applications ranging from host-guest interactions [4] with metallic ions [5] and neutral molecules to biomedical research [6,7], chromatography [8], electrochemical and luminescent sensors $[9,10,11]$ and catalysis [12].

a Facultatea de Chimie şi Inginerie Chimică, Universitatea Babeş-Bolyai Cluj-Napoca, Str. Arany Janos, $n r$ 11, RO-400028.

b Institutul de Cercetări în Chimie Raluca Ripan, Universitatea Babeş-Bolyai Cluj-Napoca Str. Fântânele, nr. 30, Cluj-Napoca RO-400294, *marioara.moldovan@ubbcluj.ro

c Facultatea de Ingineria Materialelor si a Mediului, Universitatea Tehnică din Cluj-Napoca, Bulevardul Muncii 103-105, RO-400641, *ovidiu.nemes@sim.utcluj.ro 
A new and exciting field in which calixarenes have recently shown their potential is their use as interfaces towards new materials $[13,14,15]$. The use of calixarenes as coupling agents assures a better binding to the inorganic material due to multiple connection sites and could increase their elasticity by concurrently taking over the stress on all four connectivity points $[16,17]$.

This work presents a new functionalization method of short glass fibers with substituted calix[4]arene as well as the thermal behavior of the new product and their precursors together with the characterization of the studied systems.

\section{RESULTS AND DISCUSSION}

New inorganic based materials were prepared by the deposition of lower rim tetracarboxyl functionalized para-tertbutyl-calix[4]arene 2 onto short glass fibers of G14 type. Calix[4]arene systems were chosen for their relative good solubility when compared to their larger analogues and their preference to adopt a cone conformation, which is more favorable for their study as coupling agents.

The preparation of the organic macrocycle 2 (Scheme 1), was achieved through the methods described in the scientific literature, starting from the commercially available para-tert-butyl calix[4]arene $\mathbf{1}$. Derivative 2 was obtained in a two step reaction, and after the purification and separation of the obtained solid, its structure was confirmed by ${ }^{1} \mathrm{H}$ NMR, FT-IR and MS studies, giving results similar to those already described in the literature $[18,19,20]$.

The new product glass fibers-tetracarboxyl functionalized paratertbutyl-calix[4]arene 3 (Scheme 1) was obtained by the deposition of calixarenic coupling agent 2 in dilute solutions of ethanol and acetone on short glass fibers type $\mathrm{G} 14$.

The methods employed for this deposition consists in the preparation of dilute solutions of functionalized calixarene $2(5 \%)$ in acidified ethylic alcohol 3a (method 1) or acetone 3b (method 2). Fine grinded type G14 glass fibers were added to the prepared solutions and the obtained mixture was stirred at room temperature.

After drying, washing and thermal treatment, the resulted products were granulometrical sorted and characterized by means of FT-IR spectroscopy, thermogravimetric analysis and electron microscopy (SEM and TEM). 


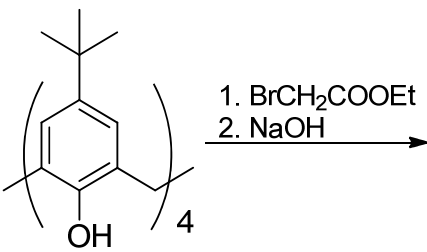

1

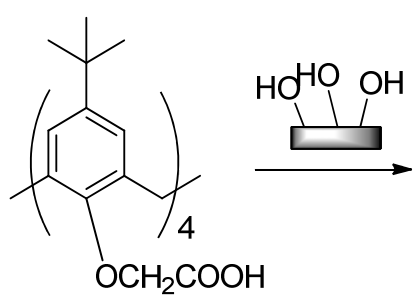

2

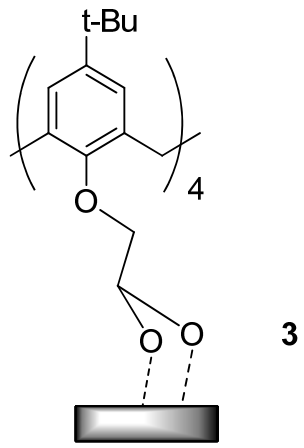

Scheme 1

In order to fully comprehend the thermal behaviour of the products $3 \mathbf{a}$ and $\mathbf{3 b}$, their thermograms, together with the ones of the non-modified glasses, calix[4]arene 1 and functionalized calix[4]arene 2 have been recorded (Figure 1).
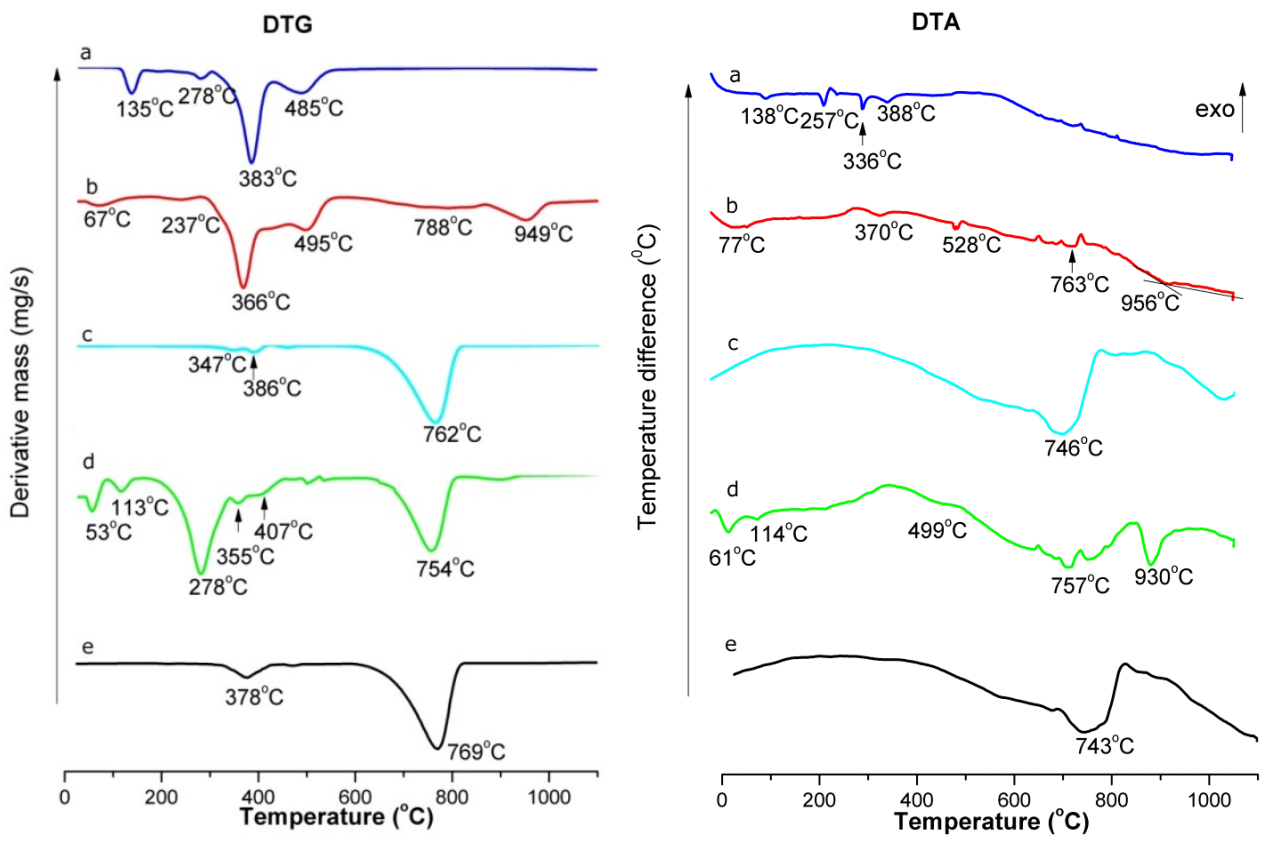

Figure 1. DTG and DTA plots for (a) para-tert-butylcalix[4]arene 1, (b), para-tertbutylcalix[4]arene acetic acid 2, (c) glass fibers, (d) product 3a (glass fiber functionalizad calixarene) in alcohol, (e) product $\mathbf{3 b}$ (glas sfiber functionalizad calixarene) in acetone. 
Analysing the recorded thermograms, for products $\mathbf{3 a}$ and $\mathbf{3 b}$, it is clearly to notice a better deposition onto glass fibers by the use of an acidulated solution of ethanol (method 1, Figure 1d). For product 3a, two important weight loss intervals can be evidenced: $16.1 \%$ in the temperature range of $160-340^{\circ} \mathrm{C}$, corresponding to the decomposition of the tetraacid calix[4]arene 2 [21], and a second mass loss of $15.0 \%$ in the $540-1100^{\circ} \mathrm{C}$ range, which clearly represents the decomposition of the G14 type glass fibers. For the functionalized tetraacid calix[4]arene 2 (Figure $1 \mathrm{~b}$ ) the first significant weight loss of $38.1 \%$ in the $280-460^{\circ} \mathrm{C}$ temperature range correlates to the similar decomposition observed in case of product $3 a$. The fact that the peak temperature for the decomposition in case of $3 \mathbf{a}\left(278^{\circ} \mathrm{C}\right)$ is substantially lower than in case of functionalized calixarene 2, denotes the functionalization of the glass fibers. The thermal stability of the functionalized calixarenes decreased $[21,22]$ if the functional groups grafted at the lower rim of the macrocycles are connected tu the inorganic substrate [23].

On the other hand, analyzing the recorded DTG and DTA of the system $\mathbf{3 b}$ (Figure 1e), the obtained plot is almost identical to the starting glass fibers, which sugests that the deposition of the calixarenic coupling agent from acetone solution did not occurred as expected, and if it did, it was to a very small extent.

The FT-IR spectra (Figure 2) confirm the results of the thermogravimetric analysis previously discussed. The spectra measured for compounds $3 \mathbf{a}$ and $\mathbf{3 b}$ suggest furthermore that the deposition of the calixarenic coupling agent in alcohol gives the expected results. The broad bands specific to the $-\mathrm{OH}$ functional groups around $3500 \mathrm{~cm}^{-1}$ for compound 2 are less significat in the spectrum of product $\mathbf{3 a}$, suggesting their involvement in the interactions with the surface of the inroganic substrate. The characteristic bands for the organic moieties of calixarenic macrocile are situated in the specific range, accordingly with the literature [1, 24, 25].

For a complete characterization of the product $\mathbf{3 a}$ and $\mathbf{3 b}$, a morphological study using scanning electron SEM (Figure 3) and transmission electron microscopy TEM (Figure 4) respectively was realized. 


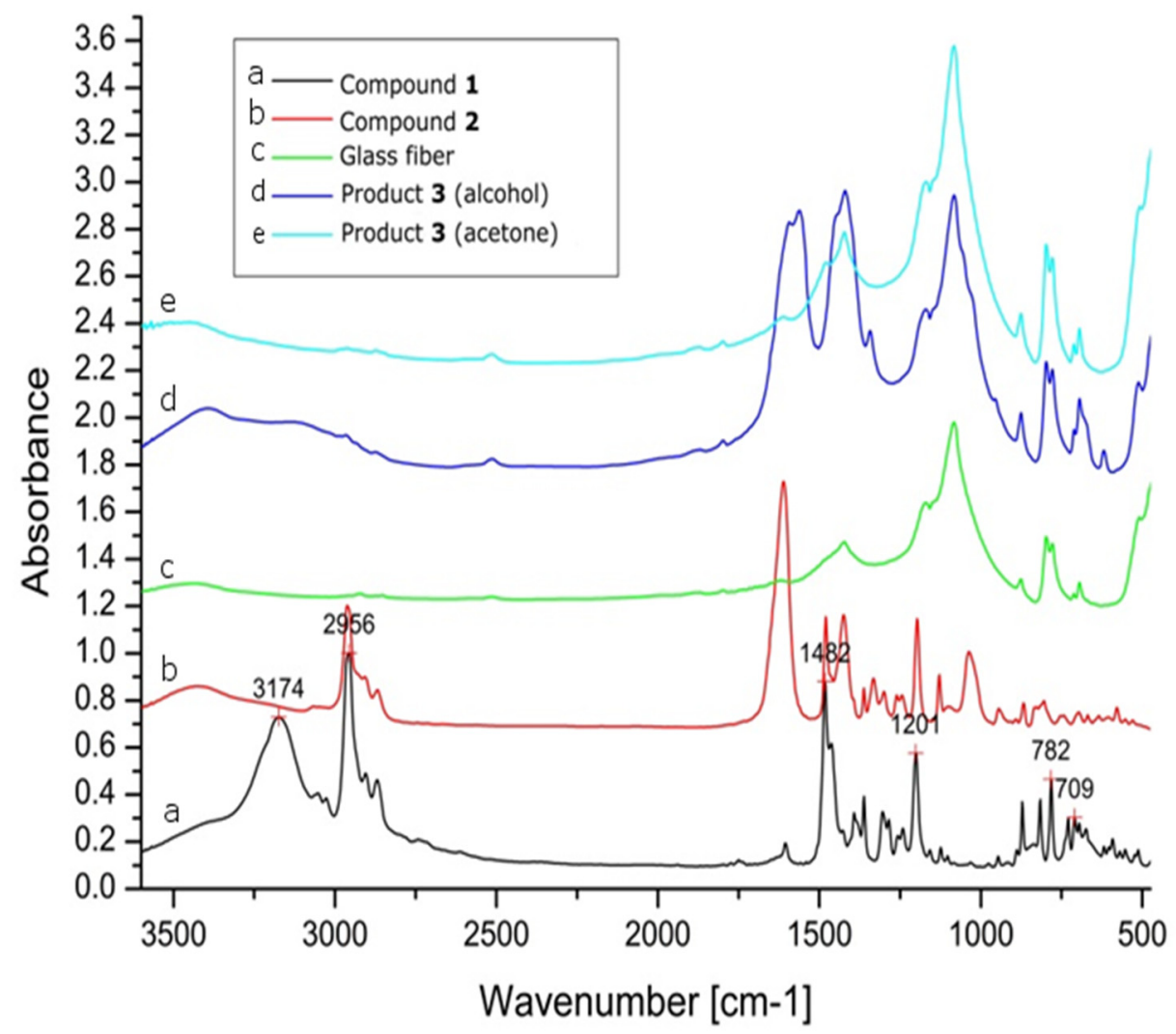

Figure 2. IR spectra of para-tert-butylcalix[4]arene 1 (a), para-tert-butylcalix[4]arene acetic acid $\mathbf{2}$ (b), glass fibers (c), system 3a (glass fiber - functionalizad calixarene) in alcohol (d), system $\mathbf{3 b}$ (glass fiber - functionalizad calixarene) in acetone (e).

SEM images suggest that, in the case in which the functionalization of the glass fibers has been achieved in acidulated solution of alcohol, the deposition of the functionalized calixarene $\mathbf{2}$ is much more efficient than if the process is undertook in acetone (Figure 3 ). 


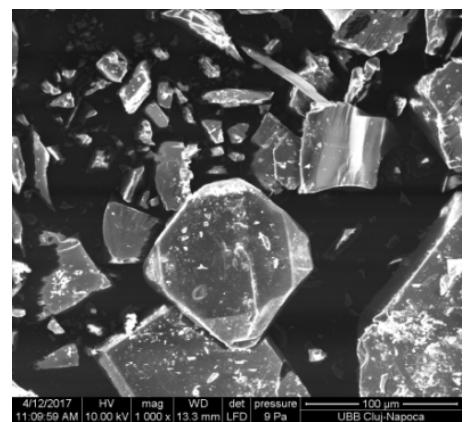

Glass particles $(100 \mu \mathrm{m})$

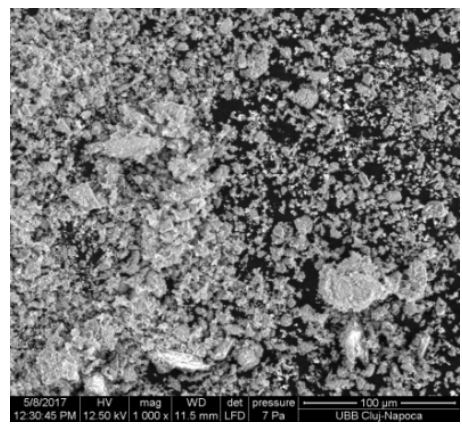

Product 3a $(100 \mu \mathrm{m})$

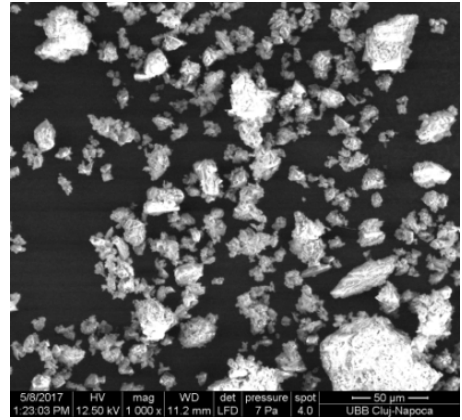

Product 3a $50 \mu \mathrm{m}$

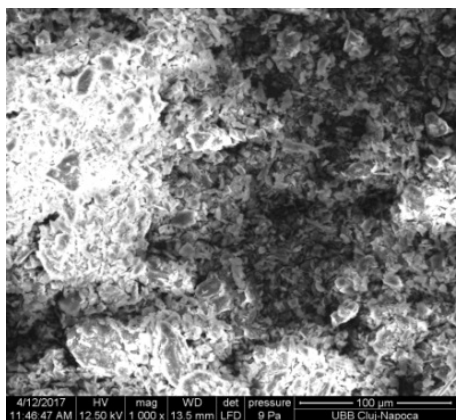

Para-tert-butylcalix[4]arene acetic acid $(100 \mu \mathrm{m})$

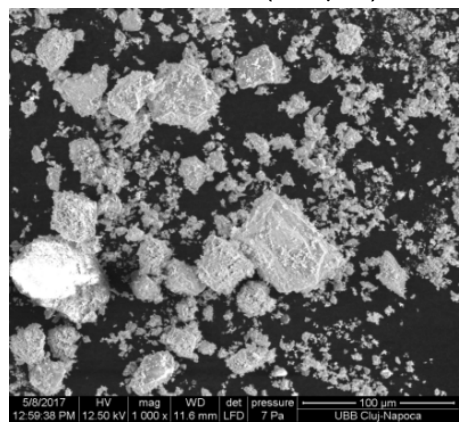

Product 3b $(100 \mu \mathrm{m})$

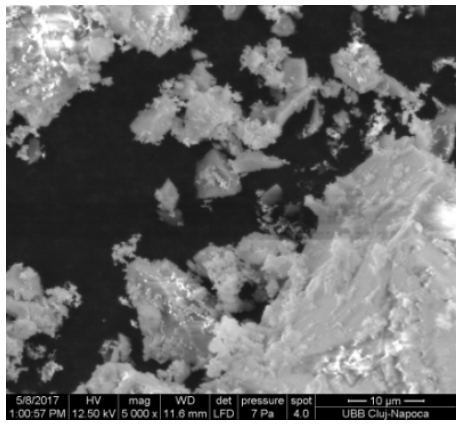

Product 3b $10 \mu \mathrm{m}$

Figure 3. SEM images of used glass fibers, acid functionalized calixarene 2 and the products $\mathbf{3} \mathbf{a}$ and $\mathbf{3} \mathbf{b}$.

The SEM images of the precursors suggest a clean flat surface in the case of the glass fibers while the acid functionalized calix[4]arene 2 shows a needle-like surface sharp form $\mathbf{3 a}$. The images recorded for $\mathbf{3 a}$ show the deposition of a continuous layer of coupling agent on the glass surface, while for the product $\mathbf{3 b}$, the changes of the glass surface are less obvious. 


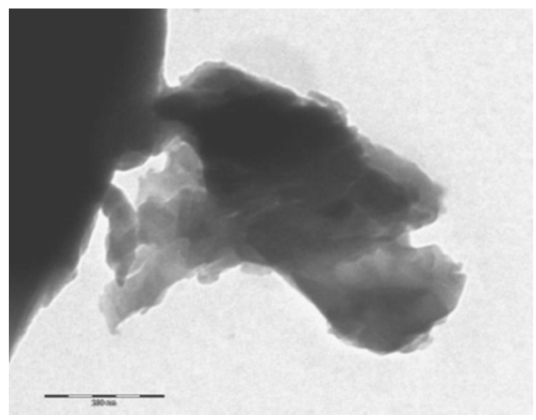

Product $3 \mathbf{a}(300 \mathrm{~nm})$

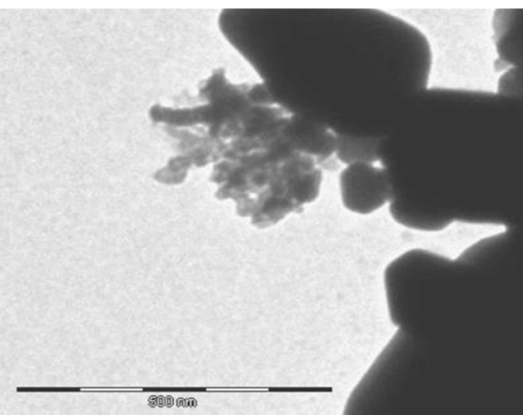

Product 3b $(500 \mathrm{~nm})$

Figure 4. TEM images of product glass fiber - functionalizad calixarene.

The results obtained by SEM are supported by TEM analysis, in which a more uniform deposition in the case of $\mathbf{3 a}$ compared to $\mathbf{3 b}$ can be observed (Figure 4).

The complex morphostructural analysis carried out show that the new material has been formed.

\section{CONCLUSIONS}

This work presents the successful binding of tetraacetyl functionalized calix[4]arene to short glass fibers of type G14. The deposition of the macrocycle to the glass surface has been done through a novel method, in acidified alcohol solution. The new system together with his precursors were characterized by specific methods including FT-IR, DTG, SEM and TEM, which prove the presence of interactions of the functionalized calixarenic macrocycle system on the inorganic substrate.

\section{EXPERIMENTAL}

All the chemicals were used as purchased without any further purification with the exception of THF which was distilled from Na/benzophenone before using.

The ${ }^{1} \mathrm{H}$ NMR spectra were recorded on a Bruker Avance $400 \mathrm{MHz}$ spectrometer in $\mathrm{CDCl}_{3}$, with TMS as reference at a frequency of $400.13 \mathrm{MHz}$.

The thermal behavior of the samples was investigated by thermogravimetry (TG) differential thermal analysis (DTA) and derivative thermogravimetry (DTG) using a Mettler Toledo TGA/SDTA851 instrument in alumina crucible, with a heating rate of $10 \mathrm{C} \mathrm{min}^{-1}$ under nitrogen flow of $50 \mathrm{~mL} \mathrm{~min}^{-1}$. 
The scanning electron microscopy experiments were performed on an Inspect S microscope (FEY Company). The TEM images were obtained using a Hitachi Automatic TEM H7650 system (accelerating voltage 40-120 kV, zoom 200x-600000x)

\section{Synthesis of product 2}

Step 1: $3.40 \mathrm{~mL}$ of ethyl bromoacetate $(5.029 \mathrm{~g}, 30.11 \mathrm{mmol})$ were added to a suspension of $1 \mathrm{~g}(1.54 \mathrm{mmol})$ of para-tert-butylcalix[4]arene and $1.655 \mathrm{~g}(69 \mathrm{mmol}) \mathrm{NaH}$ in $30 \mathrm{ml}$ of THF. The resulting mixture was refluxed for one hour, quenced in water after cooling and filtered to yield $1.37 \mathrm{~g}$ of tetraethyl calix[4]arene acetic ester (95\% yield). The obtained ester was characterized by ${ }^{1} \mathrm{H}$ NMR giving resonance signals in the ranges described by the literature. [19]

Step 2: A Mixture of $1.37 \mathrm{~g}$ brute tetraethyl calix[4]arene acetic ester (1.381 mmol), $25 \mathrm{~mL}$ of methanol and $600 \mathrm{mg}$ of $\mathrm{NaOH}(5.524 \mathrm{mmol})$ dissolved in $10 \mathrm{~mL}$ of water was refluxed for an hour. After cooling, water was added to the reaction mixture. The off-white waxy solid was filtered and washed with several portions of acetone $(5 \times 10 \mathrm{~mL})$ to yield 2 as a white powder. The derivative was characterized by ${ }^{1} \mathrm{H}$ NMR, MS and FT-IR giving similar results to those reported in the literature.[20]

\section{Deposition of the organic coupling agent on the glass fibers}

The functionalized calix[4]arene was deposited on the glass fibers by dissolving into an alcoholic solution (90 ethanol and 10\% distilled water) acidified to a pH of 3.5-4 by means of glacial acetic acid. Due to the low solubility of the macrocycle, a $5 \%$ (in weight) solution was used for the deposition. $10 \mathrm{~mL}$ of this solution was added to $2 \mathrm{~g}$ of finely grinded $\mathrm{G} 14$ glass fibers. The mixture was vigorously stirred for 1 hour at room temperature. The thick white paste thus obtained was allowed to dry, in air. After 2 days at room temperature, the resulted product was fixated by thermal treating at $70^{\circ} \mathrm{C}$, in a $1 \mathrm{~cm}$ layer for 7 hours. The final product was obtained after sieving through a vibrating sieve $(50 \mu \mathrm{m})$. The deposition in acetone was achieved in the same manner by dissolving the functionalized calix[4]arene in acetone $(5 \%$ weight solution) and following the same working procedure.

\section{ACKNOWLEDGMENTS}

O.N. thanks for financial support to UEFISCDI by project number PN-IIIP2-2.1-96BG-2016. M.M. thanks UEFISCDI for partial financial support by project 101-PED-2017. The authors would like to thanks Dr. Gabriel Katona for recording the TEM images. 


\section{REFERENCES}

1. C.D. Gutsche, J.F. Stoddart, "Calixarenes Revisited", The Royal Society of Chemistry, Cambridge, 1998.

2. C. Wieser, C.B. Dieleman, D. Matt, Coordination Chemistry Reviews, 1997, 165, 93.

3. L. Baldini, A. Casnati, F. Sansone, R. Ungaro, Chemical Society Reviews, 2007, 36, 254.

4. J. Rebek, Chemical Communications, 2000, 8, 637.

5. F. Zhang, Y. Sun, D.M. Tian, W.S. Shin, J.S. Kim, H.B. Li, Chemical Communications, 2016, 52, 12685.

6. M.A. Hussain, M.U. Ashraf, G. Muhammad, M.N. Tahir, S.N.A., Current Pharmaceutical Design, 2017, 23, 2377.

7. E.V. Ukhatskaya, S.V. Kurkov, S.E. Matthews, T. Loftsson, Journal of Pharmaceutical Sciences, 2013, 102, 3485.

8. M. Sliwka-Kaszynska, Critical Reviews in Analytical Chemistry, 2007, 37, 211.

9. C.P. Han, H.B. Li, Analytical and Bioanalytical Chemistry, 2010, 397, 1437.

10. J.S. Kim, D.T. Quang, Chemical Reviews, 2007, 107, 3780.

11. D. Diamond, M.A. McKervey, Chemical Society Reviews, 1996, 25, 15.

12. S.Y. Li, Y. W. Xu, J.M. Liu, C.Y. Su, International Journal of Molecular Sciences, 2011, 12, 429.

13. J. Kulesza, B.S. Barros, S. Alves, Coordination Chemistry Reviews, 2013, 257, 2192.

14. S. Hutchinson, G.A. Kearneym E. Horne, B. Lynch, J.D. Glennon, M.A. McKervey, S.J. Harris, Analytica Chimica Acta, 1994, 291, 269.

15. S. Friebe, S. Gebauer, G.J. Krauss, G. Goermar, J. Krueger, Journal Of Chromatographic Science, 1995, 33, 281.

16. O. Gezici, M. Bayrakci, Journal of Inclusion Phenomena and Macrocyclic Chemistry, 2016, 83, 1.

17. R. Ranete, P.M. Petrar, R. Septelean, I. Perhaita, G. Nemes, Studia Universitatis Babes-Bolyai Chemia, 2015, 60, 15.

18. A. Arduini, A. Pochini, S. Reverberi, R. Ungaro, Journal Of The Chemical Society-Chemical Communications, 1984, 15, 981.

19. K. Iwamoto, S. Shinkai, Journal of Organic Chemistry, 1992, 57, 7066.

20. W. Wang, S. Gong, Y. Chen, J. Ma, New Journal of Chemistry, 2005, 29, 1390.

21. A. Saponar, E.-J. Popovici, I. Perhaita, G. Nemes, A.-I. Cadis, Journal of Thermal Analysis and Calorimetry, 2012, 110, 349.

22. H. Deligoz, O. Ozen, G.K. Cilgi, H. Cetisli, Thermochimica Acta, 2005, 426, 33.

23. S. Ozkinali, H. Kocaokutgen, Journal of Molecular Structure, 2013, 1031, 70.

24. A. Saponar, E-J. Popovici, N. Popovici, E. Bica, G. Nemes, P. Petrar, I. SilaghiDumitrescu, Revista de Chimie, 2009, 60, 278.

25. V.L. Furer, E.I. BorisoGlebskaya, V.I. Kovalenko, Spectrochimica Acta Part A, 2005, 61, 355. 
